\title{
Process mapping for road works planning and coordination
}

\author{
Rizwana Shaheen Hussain \\ School of Civil and Building Engineering, Loughborough University, \\ Loughborough, UK and \\ Communities and Place, Derby City Council, Derby, UK \\ Kirti Ruikar and Marcus P. Enoch \\ School of Civil and Building Engineering, Loughborough University, \\ Loughborough, UK, and \\ Nigel Brien and David Gartside \\ Communities and Place, Derby City Council, Derby, UK
}

\begin{abstract}
Purpose - Diminishing local government budgets and the need to reduce highway works activities necessitate cost effective and efficient processes. The purpose of this paper is to investigate streamlining road works administrative processes to enhance coordinated working at Derby City Council.

Design/methodology/approach - Case study research of a local authority was undertaken using business process mapping. Specifically, Swimlane analysis enabled re-engineering of business processes from design stage, to works permit issuance. Process improvement recommendations were validated by nine industry experts through a focus group and semi-structured interviews. A logic map was developed for transferability to other councils, identifying key attributes for a successful administrative road works management process.

Findings - Research revealed inherent silo working and processes built around fragmented IT systems creating process inefficiency. Validation found numerous practices and management styles were culturally embedded and common across councils. Peer reviewed recommendations are made to improve working practices, including improving IT systems, removing process bottlenecks, and training staff.

Research limitations/implications - Whilst road works management policy is generally under-researched, its strategic and negative impacts are widely acknowledged. This study highlights the day-to-day operational problems which are interconnected to the strategic impact, bridging an important gap in knowledge, as well as adding to business process re-engineering literature.
\end{abstract}

Originality/value - The research adds to a limited body of road works management policy research, and also presents a high-level logic map for councils to adopt as appropriate.

Keywords Case studies, Management, Construction management, Efficiency, Public sector,

Business analysis, Transport, Process analysis

Paper type Case study

\section{Introduction}

Public highway works (utility works and highway maintenance) management increasingly requires enhancement to minimise its negative impacts on society including, congestion, depleted structural life, compromised air quality, local business losses, general public

(c) Rizwana Shaheen Hussain, Kirti Ruikar, Marcus P. Enoch, Nigel Brien and David Gartside. Published by Emerald Publishing Limited. This article is published under the Creative Commons Attribution (CC BY 4.0) licence. Anyone may reproduce, distribute, translate and create derivative works of this article (for both commercial and non-commercial purposes), subject to full attribution to the original publication and authors. The full terms of this licence may be seen at http://creativecommons.org/licences/by/4.0/legalcode

This research was conducted at the Centre for Innovative and Collaborative Construction Engineering, Loughborough University. Thank you to the ESPRC (Grant Number EP/G037272/1) and Derby City Council for funding and support, and special thanks to HAUC UK, Sheffield City Council, Kent County Council for their insightful contributions.

Received 31 August 2016 Revised 7 December 2016 10 February 2017 Accepted 1 March 2017 
BEPAM

7,2

inconvenience and aesthetic depreciation (Brady et al., 2001; Hussain et al., 2016; Lepert and Brillet, 2009; Matthews et al., 2015; Transport Research Laboratory, 2009; Walker and Calvert, 2015). Moreover, UK utility construction cost around $£ 1.5$ billion annually, whilst wider societal costs are estimated far higher - around $£ 5.6$ billion annually, of which $£ 5.1$ billion comprises driver time alone (McMahon et al., 2005). More recent utility construction costs by the National Joint Utility Group (NJUG) lie at around $£ 2$ billion (Bennett, 2014).

Derby City Council (DCC) recognises the aforementioned undesirable symptoms and adopted a Permit Scheme in 2013 to exercise greater control of planning and coordinating highway activities. However, industry stakeholders regard that inefficient back office business processes hold back efficient on-street operations (Hussain et al., 2016). Therefore, the study rationale is to investigate whether process efficiencies can be gained through reviewing business process activities. Although highway works incorporate both road works (highway maintenance works) and street works (utility works), DCC seeks to investigate internal business processes given the greater ability to influence intra-organisational change, before encouraging utility stakeholders' participation. A logic map is also developed for wider adoption by other local authorities (LA). This research is timely, because sustained Highway Authority (HA) budget cuts force additional powerful incentives for efficient working. The remaining paper details the literature review, method, findings, a road works planning logic map, discussion and a conclusion.

\section{Process efficiency in highways management}

Great Britain's local road network comprising around 238,000 miles is statutorily managed by LAs; the strategic road network of around 7,600 miles of mainly motorways and trunk roads is controlled by Highways England, Transport Scotland and the Welsh Government, respectively (Department for Transport, 2016). However, communities living and working in LA areas necessitate basic utilities such as energy, water and telecoms, leading to more highway cuts on local roads (Marvin and Slater, 1997). Whilst a structured and efficient approach for managing highway works is clearly required (Brady et al., 2001; Zhang, 2016), English LA highway works coordination processes are reported to be weak, superficial, and lacking ownership and coordination effort (Hussain et al., 2016).

One way of reviewing works is through business process re-engineering (BPR), comprising radical process re-design to make significant organisational service, quality and cost improvements (Hammer and Champy, 2001). BPR distinguishes value adding and non-value adding activities, which assist process streamlining. Despite manufacturing origins, BPR is increasingly popular in office environments, and now government (Niehaves et al., 2013). However, unique public sector characteristics make removing non-value adding activities, and adopting private sector BPR lessons difficult. Unique characteristics include their non-profit driven nature, legal/formal constraints, accountability and honesty expectations, bureaucratic hierarchal structures, political influence, and reduced decision-making autonomy amongst personnel (Janssen and Cresswell, 2005; Kamal et al., 2015; Thong et al., 2000). Nevertheless, stakeholder expectations for efficient processes, and enhanced process and information technologies (ITs) synchronicity, mean that government BPR remains advocated (Gulledge and Sommer, 2002; Weerakkody et al., 2011; Weerakkody and Dhillon, 2008).

Process efficiency in highways management has been sought previously. For example, process improvements have made lengthy business processes faster and cheaper for Pennsylvania Department of Transport, who automated parts of the highways defect management process to hand-held mobile inspection devices leading to significant cost savings (Tomassini, 2014). Separately, Highways England adopted an alliance and partnering framework - the construction management framework (CMF), to improve procurement processes and collaborative working arrangements in major maintenance projects. 
Applying partnering principals of mutual trust and cooperation, the CMF emphasised the importance of communication and close working (Ansell et al., 2009). Additionally, "lean" helped improve process efficiency and added value to highways projects. For example, the UK's Highway Maintenance Efficiency Programme (2013) report a lean review of pothole response activities, leading to revised processes, practices and equipment at Walsall Council. Ansell et al.'s (2007) study on Highways England's maintenance project (construction phase) found that lean working enabled greater emphasis on advanced formal planning, encouraging workforce discipline and focus on forthcoming tasks. The study stressed the importance of training operatives on lean principals to ensure wider understanding and sustained buy-in, and critically effective leadership to ensure project ownership. Indeed, lean construction was considered "the biggest opportunity for improving operational productivity" (Wolbers et al., 2005). However, construction sector BPR and lean have been criticised as damaging rhetoric for efficient and streamlined working, which actually undermine the construction workforce. To enable process "optimisation", people in the construction supply chain are treated as passive objects. Furthermore, contractors are forced to lower costs whilst improving delivery, which exacerbates entrenched adversarial working cultures (Green, 2011; Green and May, 2003); therefore the entire impact of process improvement activities requires consideration.

Whilst high-level process improvement cases are highlighted, literature at the tactical and operational levels, particularly in LAs is scarce. Therefore, LA operational level research issues is required, because it has a direct impact on on-site works execution, and currently this complex arena is under-researched.

\section{Method}

A case study approach was most suited to investigating the business processes of an LA because it enabled immersive and in-depth understanding of the authority's processes, whilst also providing rich subject data access in its contextual setting (Yin, 2014). Derby city was selected as representative of a fairly typical medium sized urban English regional city, of around 250,000 with a Permit Scheme. For this study three team processes were examined: Highways Maintenance and Highways Engineering teams, as the HA who were "work promoters", and the Network Management team as the Street Authority (SA) who act as the regulator.

As a key BPR component, business process mapping (BPM) was utilised to document DCC's administrative processes. BPM enables the understanding, investigation and evaluation of complex business processes for efficiency and effectiveness, supporting redesigned processes for improved outcomes (Biazzo, 2000). Amongst various BPM techniques considered, Swimlane diagrams (Sharp and McDermott, 2001) were selected for their ability to map complex, multi-actor processes (and sub-processes) simply. The study relied on DCC experts for process knowledge, thus snowball sampling was used to select two "core" process experts from each team. Workshops were undertaken with process experts, where processes were recorded on large sheets using sticky labels - additional comments were manually recorded. Processes were subsequently documented into Swimlane diagrams and subjected to an iterative process of amendment and approval, until process experts approved final versions. Detailed analysis of comments were undertaken using Bryman's thematic content analysis, comprising: text analysis, coding and categorising salient terms, and theming codes together (Gibbs, 2011).

The validation exercise required convenience and purposive sampling to invite middle and senior Highways Managers from eight LAs (constituting neighbouring LAs, or LAs regarded highly for road works management), and representation from the Highways Authority and Utilities Committee (HAUC). Three LAs, a senior HAUC member and six DCC
Road works planning and coordination 
BEPAM

7,2 managers ultimately participated in the study. "Experts" constituted those with interpretative and technical process orientated knowledge (Miles and Huberman, 1994).

The author developed a sequential eight step path to conduct this study, as detailed in Table I.

\section{Findings}

This section reports findings from the eight step approach adopted to conduct, analyse and draw recommendations for this study.

\section{Stage 1 - understanding the business context and position}

Derby is a fairly typical English regional city of around 250,000 people, with a unitary LA. Central government's sustained national budget cuts have created unprecedented financial pressures in Derby. The council strategically aims to be a modern and resilient authority ensuring that "every pound and hour is productive" (Derby City Council, 2016a). Departmentally, Streetpride report $£ 19$ m annual savings to date, and propose a "lean" review of highway services seeking further efficiencies and savings (Derby City Council, 2016b). Since 2013, the council provides an in-house direct labour organisation (DLO) for highway works to maximise value.

The council is dutybound to maximise road capacity through managing the highway network expeditiously and minimising road works and street works activity, thus the Derby Permit Scheme was introduced to take greater control over highway occupation (Derby City Council, 2013). All works executers must now have a Permit to work on "traffic sensitive streets," which are free to HAs.

\section{Stage 2 - securing management commitment}

High levels of management commitment is required to mobilise change and reduce project failure, particularly in LAs where organisational culture is entrenched, risk averse and change resistant (Cresswell et al., 2013; Lines et al., 2015). Therefore, buy-in was secured by the departmental director, and the relevant divisional heads of service, due to their positions and ability to direct change.

\section{Stage 3 - parameters of study}

Business process review spanned the Highways Maintenance, Highways Engineering and Network Management teams, as they were directly involved in road works (comprising road maintenance and rehabilitation, and breaking or excavation activities). The study was limited to back office processes, from scheme design to Permit issuing stage, and included "standard" (three to ten days) and "major" (over ten days) works, as these facilitated greatest scope for collaborative working. Minor (less than three days), "emergency" and "urgent" works were excluded as it was considered disproportionate, inconvenient and potentially unsafe to delay these works.

\section{Stage 4 - analysis of core functions and processes}

Core experts assisted in the iterative exercise of process mapping as defined in stage 3. Highways Engineering's projects were found to be large and recorded on the annual work programme, whereas Highway Maintenance works were more routine, reactive and smaller natured. The headline stages of highway design and maintenance consisted of receiving enquiry, investigation, detailed design, work scheduling and cost production, contractor procurement, programming works, submitting a Permit application and awaiting an outcome. The Network Management team, as a SA, processed Permit applications and sought to coordinate highway activities. Figure 1 details the high level process maps documenting the hand-off between the actors across the current team processes. 


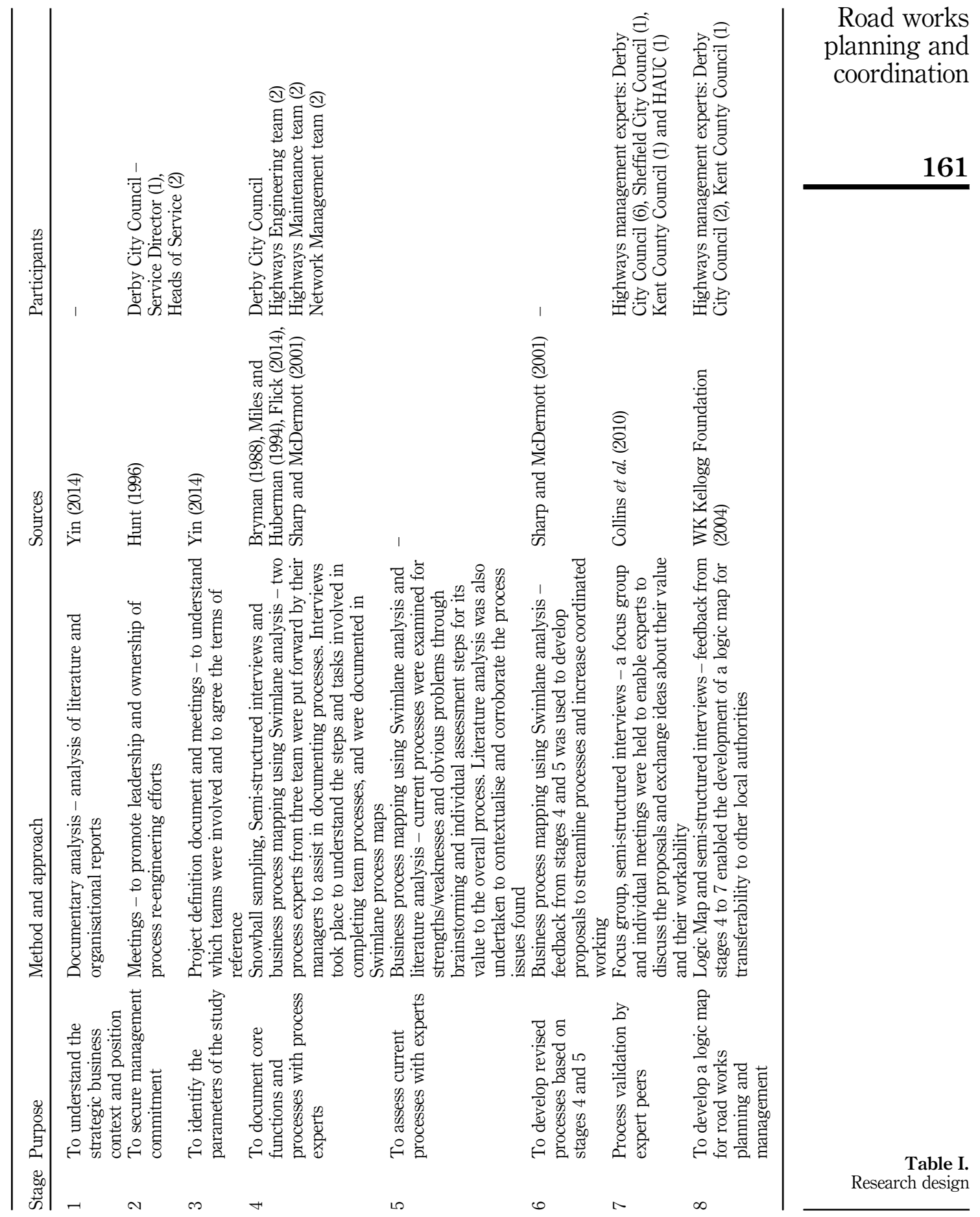


BEPAM

7,2

162

Figure 1.

High level process maps for highways maintenance, highways engineering and network management teams

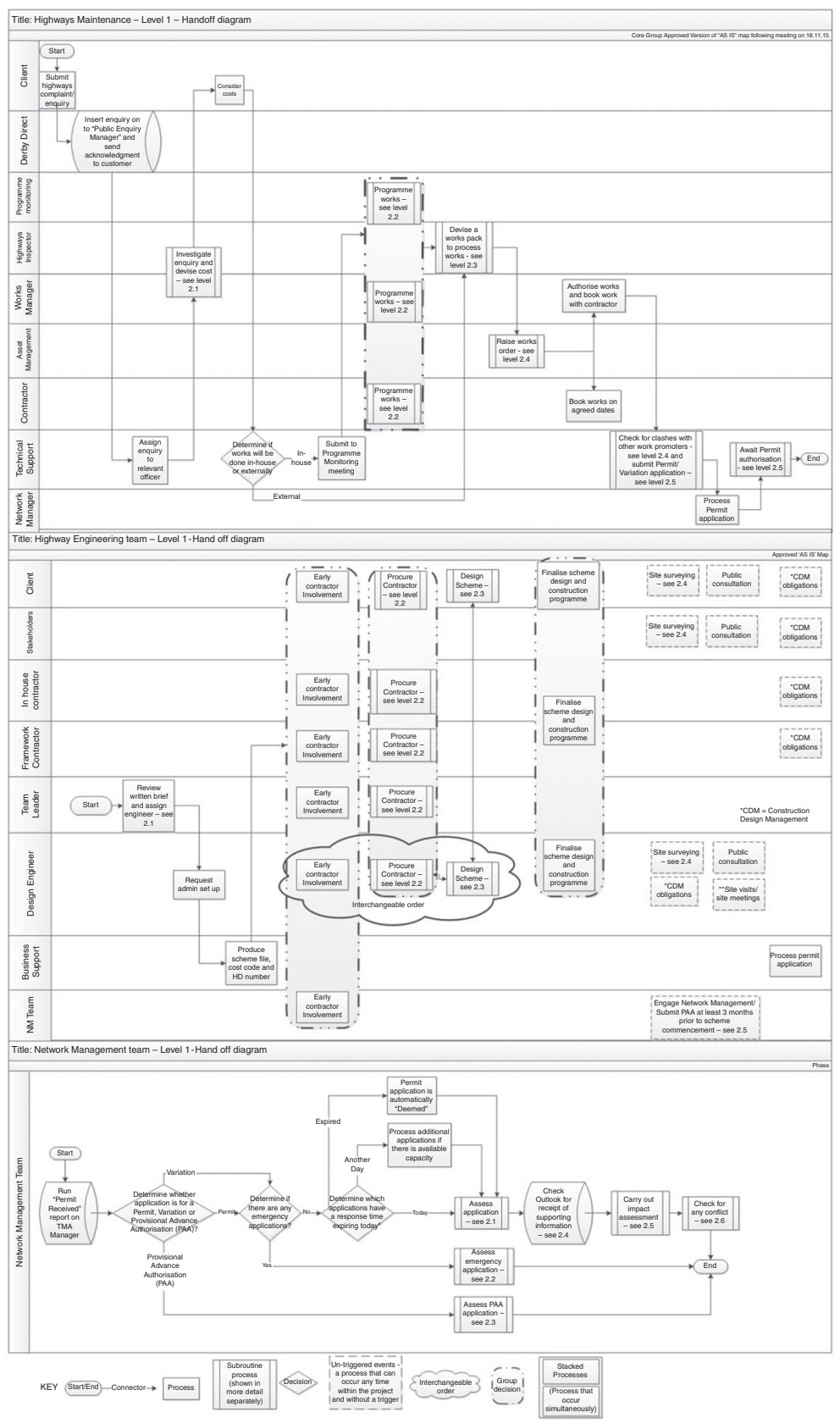

Stages 5 and 6 -assessment of current processes and development of new processes This section examines the issues found across the teams. Although findings have been categorised into IT, workflow design and human resources (HR), and policies and rules (Sharp and McDermott, 2001), in reality, the themes overlapped each other. 
IT

Throughout the study, IT was a key bottleneck in multiple ways. First, all three teams directly or indirectly relied on a combined Highways IT programme. The dual system recorded enquiries, raised works orders, and incorporated "Electronic transfer of notices" (EToN - a statutory specification to enable electronic Permit exchange) (Department for Transport, 2013). Staff had varying data access levels, with little or no formal training. The combined IT programme lacked synergy between modules, requiring duplicate data entry which created opportunities for error. Officers reported a number of issues including:

There is no efficient way of checking EToN feedback for work promoters.

We need access to EToN to check the status of Permit applications. Permits can be rejected and the Design Engineer is unaware as we are not informed. We have to rely on Tech Support to manually check the system daily.

Other key system problems included: the inability to store documents, no prompts or warnings of incoming EToN correspondence, and no simple way to produce reports. The Highways IT system was aged (over ten years old) and not fit for purpose, accordingly DCC operationalised a replacement system over the study period.

Separately, six different IT packages were used to draw/view scheme designs in the Highways Engineering team, which interrupted seamless design. An officer reported:

We need a single storage location. Currently there are different softwares, IT formats and drawing versions which can be highly problematic. People working from old drawing versions is not unheard of.

Fragmented IT is symptomatic of data management within the engineering and construction sector, characterised by high data volumes, developed by different professionals, using different IT systems (Beach et al., 2013). Poor IT system architecture and poor integration commonly contribute to process inefficiency (Edwards and Peppard, 1994). Therefore, fractured IT systems should be replaced with a single cloud based collaborative working/document management platform enabling stakeholders to design and view drawings collaboratively (Beach et al., 2013).

\section{Workflow design and HR}

IT limitations meant workflows were modelled around IT systems creating bottlenecks; bottlenecks stem from compulsory information being unavailable to staff (Sharp and McDermott, 2001). Highways Maintenance team processes were particularly fraught with bottlenecks; for example, technical administration staff would check highway availability for proposed works instead of works promoters due to restricted data access. Indeed, unnecessarily restricted data access is an outdated LA practice, which should be replaced with wider data access to expedite works (Weerakkody et al., 2011). A further example is the schedule of rates for internal DLO works which was not documented, therefore, cost estimate requests were e-mailed to a single works programme manager. This practice is not only a significant bottleneck, but also undermines organisational knowledge management. Instead, the schedule of rates should be documented ideally within the Highways IT system and be readily available on demand.

In terms of external tender and contract procurement, a team leader was heavily involved in the process, presumably to oversee it and provide advice. This example of "managerialistic model" where managerial involvement and monitoring is assumed to provide greater service, product, or behaviour, can be considered an outdated culture still common in the public sector. Instead the "professional model" should be adopted, where the assumption is that trained and qualified staff lead to high quality and professional service,
Road works planning and coordination 
BEPAM

7,2

products and behaviour (Perrott, 2002). It is recognised that government employee autonomy is restricted, however it remains a crucial ingredient for successful public organisations (Thong et al., 2000); consequently, better value could be provided if employees are trained to the same level as the team leader.

\section{Policies and rules}

Limited organisational and cross-organisational working was evident throughout the process. Statutorily prescribed quarterly coordination meetings have historically been held jointly with Derbyshire County Council, an upper tier LA responsible for numerous smaller rural councils. Although the Network Management team attended these meetings, the Highway Maintenance/Engineering teams were rarely represented. The meetings were acknowledged as weak, providing little value to the Authority, tying in with Hussain et al.'s (2016) findings that coordination meetings tended to be contrived and superficial. To address this, DCC should work with stakeholders, particularly HAUC and NJUG to devise a gold standard for coordination meetings, which should subsequently be adopted for independent Derby meetings. The meetings should also be attended by all stakeholders involved in highway works.

In terms of work planning, there was a culture of retaining planned scheme information until construction dates were more definitive, as it was perceived that stakeholders, particularly the Network Management team, were otherwise uninterested. An officer commented:

Unless we have dates and sufficient plans, Network Management don't want to hear from us.

Conversely, the Network Management team wanted more foresight of proposed works to plan network activity. Highway works can be significant undertakings, combining multi-disciplinary design, planning, materials, procurement, specialist machinery and on-site construction, requiring high level of planning, involving numerous supply chain actors. It can therefore be challenging accommodating or coordinating works in later stages of planning, particularly after finalised construction dates. Accordingly, work programmes should be availed to interested stakeholders at the beginning of each financial year (or earlier if possible) to enable wider coordination notwithstanding firm construction dates. This could be advanced by plotting future works on a map-based system incorporating scheme information and contact details for works promoters.

\section{Stage 7 - validation of road works management issues and recommendations}

A validation exercise took place to review the processes and proposals with DCC managers, peer LAs and HAUC. Table II presents the problems found in the Derby road works process along with validated recommendations for improvements. The commonalities and conflicts in opinion amongst stakeholders are provided below.

The validation exercises confirmed that road works design and management was complex and that collaborative working was challenging. The key commonalities in opinions were that:

- Coordinated working was challenging due to complexities and inherent challenges arising from individual team processes and circumstances beyond employee control, including poor IT and limited data access.

- Coordination meetings needed an improved format. Meetings should focus on large and major impact projects, whilst issues about individual streets should be addressed outside coordination meetings. Furthermore, coordination meetings should conjoin with neighbouring regional authorities to maximise effectiveness. An interviewee commented: "Coordination is very difficult - who do you send plans to as different teams represent different purposes; it can become too complicated. This discussion should be a part of wider discussions as to what coordination meetings should achieve". 


\begin{tabular}{ll}
\hline Stage of project & Problem \\
\hline 1. Receive enquiry & $\begin{array}{l}\text { Duplicate entry of enquiry across CRM } \\
\text { system and Highways IT systems }\end{array}$ \\
$\begin{array}{l}\text { 2. Investigate } \\
\text { enquiry }\end{array}$ & $\begin{array}{l}\text { Doplicate system of enquiry across modules } \\
\text { Manual process requiring paper work and } \\
\text { camera }\end{array}$
\end{tabular}

3. Detailed design Numerous design software used by different teams and disciplines across designers Poor utility response rate when requesting information about utility asset locations and future programmed works

Asset management data (lighting, signals, drainage, etc.) is not freely available, and must be obtained by contacting individual officers

4. Submit PAA Not enough advance notice is given about future major works, with less than the minimum prescribed 3 months sometimes

5. Produce work schedule and costs

6. Procure contractor

7. Programme works Programme Monitoring meetings are considered a bottleneck which provide no clear value.

The ability to check road space availability is restricted to Technical Admin staff Operational programme of works is not available for common view

8. Book works with contractor

9. Submit Permit application

10. Assess Permit application the Works Manager must be e-mailed for quotes for all individual works

Team leader micro-manages procurement

Produce paper works packs for approval and submission.

Permit applications submitted by Technical Admin staff

Not enough coordinated working with others
Recommendations

Update programmes to support vertical integration across IT systems (in progress)

Update fragmented Highways IT system with a state of the art system. This proposal could be advanced by procuring IT across regional HAs for collaborative procurement Update to portable electronic tablets to use on site, with remote access to Highways IT System (in progress) ${ }^{\mathrm{a}}$

Integrate the highways design software applications onto a single cloud based collaborative construction platform

Confirm point of contact for utility asset records and future works for individual utility companies regularly

Store asset management data in a central electronic location in an accessible format, for instant retrieval

Furnishing advance information for large impact and major works on the business plan at the beginning of the year (or earlier) with approximate dates

Set up a "safe-guarded for future works" hatch on a GIS plan for future works (HA or utility companies)

A schedule of rates is not published therefore Formalise an indicative schedule of rates for Formalise an indicative schedule of rates for
staff be able to devise an indicative cost ${ }^{\mathrm{a}}$

Team leader involvement should remain to facilitate quality assurance checks ${ }^{\mathrm{a}}$

Meetings should remain in order to facilitate joint decisions ${ }^{a}$

Staff should have direct access to road space data removing Technical Admin Team staff from the process entirely

Operational work programme should be accessible on IHMS and visible across the service area

electronic (in progress)

The peric (in progress)

with the Technical Admin team ${ }^{\mathrm{a}}$

Report proposals, with potential sites and approximate dates for all major works at the formal quarterly coordination meeting Significant coordination efforts should be made outside of formal coordination meetings by a dedicated road works planner ${ }^{\mathrm{a}}$ HA to be represented at quarterly coordination meetings Update fragmented highways IT system with a state of the art system (in progress)

\section{Road works planning and coordination}

11. Advise applicant Manually check IT system for a response from NM

Note: ${ }^{\text {a }}$ Refer to changes proposed by stakeholders as part of the validation process

Table II.

Recommended actions for issues identified at Derby City Council 
BEPAM

7,2

166

- Highways IT systems were generally poor, fragmented and unproductive. Highways IT systems should be synergistic, web-hosted and procured regionally to reduce costs.

- Organisational collaboration was considered critical, albeit with differing degrees of collaborative working effort amongst LAs. There was consensus that work programmes should be shared and discussed to facilitate collaborative working and a broader understanding of departmental activities. In addition, there was evidence that dedicated coordination personnel were highly successful in internal and inter-organisational collaboration.

- The annualised nature of highway budgets mean that LA cannot adequately plan in advance. An interviewee commented that "this is a major issue across the country".

Examples where conflicting opinions were expressed about some recommendations are as follows:

- Although most stakeholders felt that team leader involvement in the tender and procurement process should be limited to advice and ultimate approval, DCC felt that the involvement was quality assurance which provided exceptional value for money, and thus should remain.

- The view that the Technical Admin team were best placed to manage the Permit application process and this function should remain with them.

- Overall consensus was that the schedule of rates should be formally documented; however DCC felt that this would not provide best value as it could not accurately reflect the true cost of an in-house work-force. As a compromise, an indicative published schedule of rate was preferred by the HA.

Stage 8-development of transferable logic map for road works planning management

Statutory legislation and funding cycles underpin road works practices, making processes and procedures fairly universal across LAs. Accordingly, a high-level logic map for wider transferability was developed, which is intended to aide LAs in their duty to manage and coordinate the road works and street works management processes under Section 59 of the New Roads and Street Works Act 1991. Logic maps depict how organisations', processes or strategies should work, typically incorporating the underlying context, principles, and activities/practices necessary for short, medium and long-term outcomes (W.K. Kellogg Foundation, 2004). The ADMINISTER logic map (Figure 2) was based on findings from this study, validation exercises and academic literature. Specifically, it considered the key processes in road works management, and identified the key inputs required, leading to key activities, and the support required. The logic map seeks to represent how the road works management process could be effectively and efficiently administered whilst taking into account the inputs and outputs from a range of different activities from different stakeholders. Amongst other factors it considers that skilled staff, efficient work flows, efficient data flow and the use of technology, equipment and resources could be one way to bring about a more streamlined and value adding process. It is acknowledged that there are likely to be many and wide ranging implications of adopting this logic map, of which finance and the availability of resources are two such key factors. Furthermore it is inevitable that each LA will be at different stages of "readiness" for comprehensively administering road works based on the quality of the inputs the organisation already has in place. Therefore, LAs should examine the inputs and consider the implications on resources and costs on a case by case basis. 


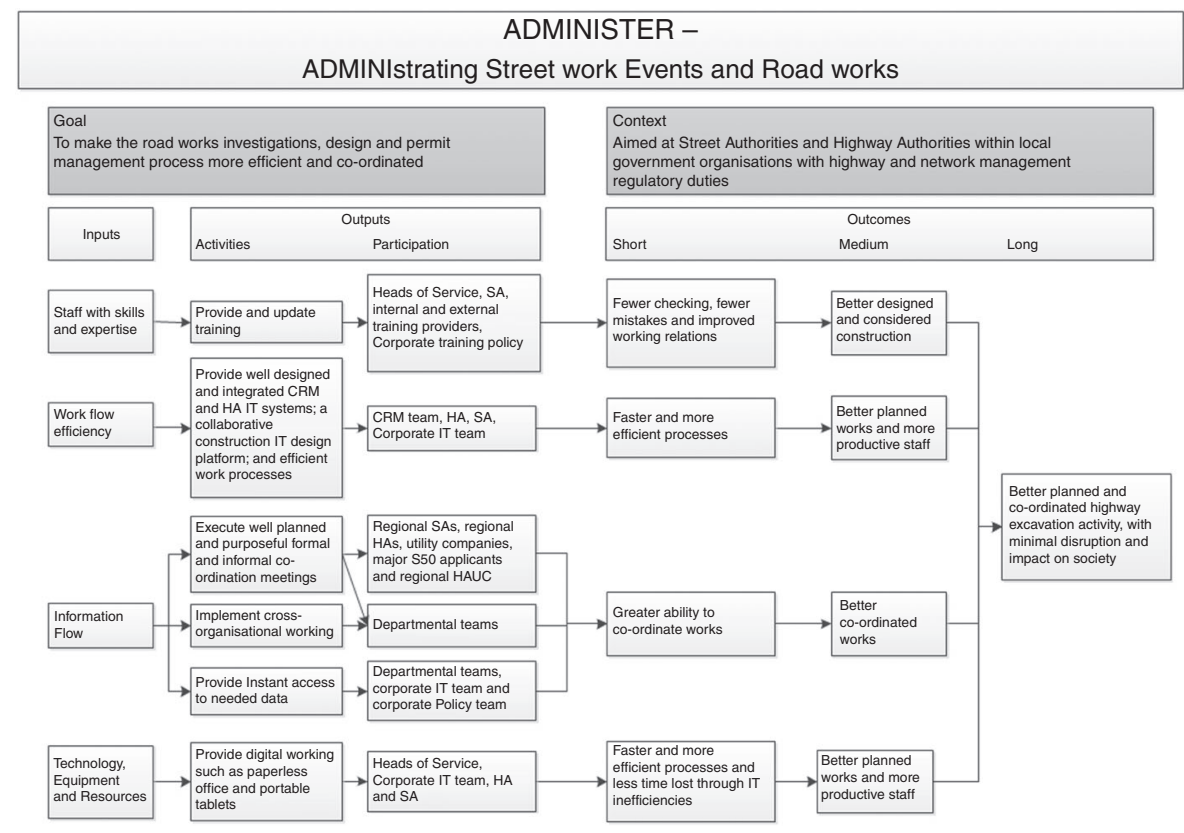

Road works
planning and
coordination

167

Figure 2.

Logic map for road works investigation, design and permit management process

A worked example of the logic map could be interpreted as follows: if an organisation has staff with skills and expertise, as a result of providing and updating training, with the possible involvement of Heads of Services, the SA, internal and external training providers and corporate training policy, it is likely to have the following effects:

- short term - empowered officers requiring fewer checks, leading to fewer mistakes and improved working relations;

- medium term - well trained officers producing well designed and considered construction projects; and

- long term - well trained officers leading to better planned and coordinated road works with minimal disruption and impact on society.

The logic map is suitable for senior managers in LAs with regulatory highway maintenance and network management functions; it seeks to achieve well planned and coordinated road works activities to provide a minimally disrupted transport network. The logic map has purposefully been kept at a high-level to ensure transferability, with individual recommendations being illustrative rather than exhaustive to enable amendment and additions as appropriate. This section will briefly consider the key inputs and activities featured in the logic map.

\section{Staff with skills and expertise}

The process review highlighted that staff were not always clear of their roles and responsibilities, and sometimes did not have the skills or training to undertake tasks correctly which can reduce morale and cause mistakes. It is important that "the right people, with the right skills, in the right jobs, are performing the right tasks" (Sharp and McDermott, 2001), therefore senior managers should ensure that staff are fully trained for example, of regulatory responsibilities and IT system usage. 
BEPAM

7,2

168

\section{Efficient workflow}

The study highlighted inefficiencies in various processes, therefore business processes should be analysed for efficiency with buy in, ownership and leadership from senior managers (Kamal et al., 2015). Further, IT enables a large proportion of processes in local government, but their inefficiency and fragmentation causes significant unproductivity and frustration. A cloud based collaborative document management portal for improved accessibility and document management for project design could be beneficial (Beach et al., 2013). IT changes usually require appropriate financial investment and corporate approval by senior managers to integrate with wider strategic LA IT initiatives.

\section{Resources and equipment}

Staff should have appropriate resources and equipment to undertake works, which includes access to functional IT systems. In addition, the construction industry is becoming increasingly automated and there is evidence that mobile computing devices have improved accessibility and operational efficiency, and could assist in the road works investigatory process (Son et al., 2012). The shift to digital working and paperless office should form part of a wider organisational strategy and would thus require senior manager approval.

\section{Shared works information}

The absence of shared information was a crucial barrier to communication, exacerbating internal and external silos; accordingly, staff should have convenient access to needed data (Weerakkody et al., 2011). Communication of works inside and outside formal coordination meetings was crucial as it provided appropriate forums to discuss and negotiate works; which is crucial for collaborative working (Lu et al., 2007). Therefore, formal coordination meetings should be well planned, purposeful, and limited to major and large works; smaller works should be discussed with appropriate parties outside coordination meetings as emphasised by the validation experts. There is also value in widening the scope of meetings to wider geographic areas to maximise value. Re-orienteering coordination meetings would require working with utility partners and neighbouring LA.

In general, organisational culture in the public sector is deeply entrenched. Organisational change requires a culture which supports it, but this is difficult in LAs because the entrenched culture is risk averse and change resistant (Cresswell et al., 2013; Kamal et al., 2015). Councils adopting the logic map must consider change management strategies, otherwise processes are likely to remain inefficient. Change needs to be championed by senior managers of the organisation to be effective, and must be backed by commitment, strategy, resources, employee support and training; otherwise improvement efforts could fail.

\section{Discussion and conclusion}

The aim of this study was twofold: first it investigated how existing highways processes could be streamlined; and second it considered how coordinated working could be enhanced. Whilst several recommendations have been made to meet these aims, and despite the overwhelming financial challenges faced by the public sector, the value of BPR could be undermined by a culture of inertia, risk aversion and resistance to innovative practices, which is common in local government (Thong et al., 2000; Janssen and Cresswell, 2005; Kamal et al., 2015). To address this, concerted change efforts are required, particularly by senior managers who have the greatest control over reorienting embedded culture. Further, intra-departmental collaborative working was undermined by inherent silo working, which is already a significant problem when also taking inter-organisational working with utility companies into account (Hussain et al., 2016). Sagacious concerns by Green (2011) and Green and May (2003) about the impact of BPR on the construction supply chain are acknowledged and would need 
to be considered prudently in any extension works directly involving construction workers. Furthermore, to provide LAs with a way to manage their statutory duty to coordinate highway works, a high-level logic map was developed for wider transferability. The map can be used as an aide to LAs to understand the key attributes to enable an efficient and effectively managed process. Of course dependent of the readiness on the LA, there may be a number of resource and financial implications which will need to be considered.

In addition, the study has shed light on general issues and practices in road works management; for which the following stakeholder recommendations are made:

(1) National Government

- Longer budget cycles are needed as annual budgetary cycles can create difficulties for HAs to plan long term works, and thus carry out long term coordination.

(2) Local Government

- greater organisational and inter-organisational communication is needed to reduce silo working, maximise coordinated working and minimise highway disruption;

- genuine senior level ownership and commitment to improving highways management is needed to help motivate and drive cultural change within organisations; and

- technology needs to fit the needs of a service, instead of processes being developed around inadequate technology.

(3) Utility sector

- widespread departmental fragmentation within utility companies needs to be addressed to enable joined-up organisational thinking; and

- genuine senior level ownership and commitment to reducing highways cuts is needed to bring awareness of the impact of utility cuts, and help drive cultural change within institutions.

Highway works policy is generally under-researched with significant need to research the operational dynamics of LAs and utility companies in planning and coordinating excavation activity. This study is important because it bridges a key gap in knowledge by drawing attention to the day-to-day operational management of road works, which precede and lead to the widely reported negative impacts of highway works. The study also adds to BPR literature by acknowledging the public sector need for BPR, whilst accepting the embedded culture of local government and severe challenges to change, reinforcing findings by previous scholars. The findings are important because they make recommendation to practitioners about road works operations and issues based on robust validation from industry experts. The study is novel as it presents a high level transferable logic map for road works managers to adopt. The limitations of this study are that it is based on a single case study of a medium sized urban LA, therefore whilst the case study may arguably not be generalisable of all LA, the headline issues presented are likely be regular discussion points of HAUC meetings across the country, and indeed similar platforms globally.

\section{References}

Ansell, M., Holmes, M., Evans, R., Pasquire, C. and Price, A. (2007), "Lean construction trial on a highways maintenance project", Proceedings IGLC-15, IGLC-15, Michigan, July.

Ansell, M., Holmes, M., Evans, R., Pasquire, C. and Price, A. (2009), "Delivering best value in highways major maintenance schemes: case study", Journal of Construction Engineering and Management, Vol. 135 No. 4, pp. 235-245. 
BEPAM

7,2

Beach, T.H., Rana, O.F., Rezgui, Y. and Parashar, M. (2013), "Cloud computing for architecture, engineering and construction sector: requirements, prototype and experience", Cloud Computing: Advances, Systems and Applications, Vol. 2 No. 8, pp. 1-16.

Bennett, E. (2014), "Interview: Bob Gallienne, Chief Executive", Utility Week, NJUG, 5 November, available at: http://utilityweek.co.uk/news/interview-bob-gallienne-chief-executive-njug/1048112 \%20-\%20.WCs_1NKLTIU\#.WOt4Ubldb4g (accessed 15 November 2016).

Biazzo, S. (2000), "Approaches to business process analysis: a review”, Business Process Management Journal, Vol. 6 No. 2, pp. 99-112.

Brady, K., Burtwell, M. and Thomson, J. (2001), "Mitigating the disruption caused by utility street works TRL report 516”, Transport Research Laboratory, Crowthorne.

Bryman, A. (1988), Quantity and Quality in Social Research, Routledge, London.

Collins, K., Onwuegbuzie, A. and Jiao, Q. (2010), Toward a Broader Understanding of Stress and Coping - Mixed Methods Approach, Information Age publishing Inc., Charlotte, NC.

Cresswell, C., Moizer, J. and Lean, J. (2013), "The role of organisational culture in the merger of English local authorities into a single unitary authority”, Local Government Studies, Vol. 40 No. 3, pp. 356-379.

Department for Transport (2013), "New Roads and Street Works Act 1991 technical specification for the electronic transfer of notices (EToN) version 6.0", DfT, London.

Department for Transport (2016), "Road lengths in Great Britain 2015 statistical release", available at: www.gov.uk/government/uploads/system/uploads/attachment_data/file/ 524087/road-lengthsin-great-britain-2015.pdf (accessed 2 February 2017).

Derby City Council (2013), "Derby City Council Permit Scheme for Road Works and Street Works Appendix 1 Additional Information", available at: www.derby.gov.uk/media/derbycitycouncil/ contentassets/documents/transport/DerbyCityCouncil-Permit-Scheme-roadworks-and-streetworks-Additional-Info-App1-June-2013.pdf (accessed 10 October 2015).

Derby City Council (2016a), “A 'Different' Council - Our Plan 2016-2019”, Derby City Council, Derby, available at: https://iderby.derby.gov.uk/media/Derby_City_Council_Plan_booklet_March_ 2016.pdf (accessed 10 October 2015).

Derby City Council (2016b), "2016-17 Department Business Plan - Strategic Partnerships, Planning and Streetpride", Derby City Council, Derby, available at: https://iderby.derby.gov.uk/media/ intranet /documents/policyandstrategy/performancemanagement/DerbyCityCouncil_CP Strategic_Partnerships_Planning\%20_Streetpride_Service_Plan_2016_2017.pdf (accessed 10 October 2015).

Edwards, E. and Peppard, J. (1994), "Forging a link between business strategy and business reengineering", European Management Journal, Vol. 12 No. 4, pp. 407-416.

Flick, U. (2014), An Introduction to Qualitative Research, Sage, London.

Gibbs, G.R. (2011), “Alan Bryman's 4 stages of qualitative analysis”, available at: www.youtube.com/ watch?v=7X7VuQxPfpk (accessed 16 January 2014).

Green, S. (2011), Making Sense of Construction Improvement, Wiley-Blackwell, Chichester.

Green, S. and May, S. (2003), "Re-engineering construction: going against the grain", Building Research and Information, Vol. 31 No. 2, pp. 97-106.

Gulledge, J. and Sommer, R.A. (2002), "Business process management: public sector implications", Business Process Management Journal, Vol. 8 No. 4, pp. 364-376.

Hammer, M. and Champy, J. (2001), Reengineering the Corporation, Nicholas Brealey Publishing, London.

HMEP (2013), HMEP Annual Plan 2014/2015, DfT, London.

Hunt, V.D. (1996), Process Mapping: How to Reengineer Your Business Processes, John Wiley \& sons, New York, NY. 
Hussain, R.S., Brien, N., Gartside, D., Enoch, M. and Ruikar, K. (2016), "Street works policy in England, UK: insights from stakeholders in England”, Infrastructure Asset Management, Vol. 3 No. 2, pp. 61-70.

Janssen, M. and Cresswell, A. (2005), "An enterprise application integration methodology for e-government”, Enterprise Information Management, Vol. 18 No. 5, pp. 531-547.

Kamal, M.M., Bigdeli, A.Z. and Themistocleous, M. (2015), "Investigating factors influencing local government decision makers while adopting integration technologies (IntTech)", Information and Management, Vol. 52 No. 2, pp. 135-150.

Lepert, P. and Brillet, F. (2009), "The overall effects of road works on global warming gas emissions", Transportation Research Part D, Vol. 14 No. 8, pp. 576-584.

Lines, B., Sullivan, K., Smithwick, J. and Mischung, J. (2015), "Overcoming resistance to change in engineering and construction: change management factors for owner organisations", International Journal of Project Management, Vol. 33 No. 5, pp. 1170-1179.

Lu, S.C.Y., Elmarghy, W., Schuh, G. and Wilhelm, R. (2007), "A scientific foundation of collaborative engineering", Annals of the CIRP - Manufacturing Technology, Vol. 56 No. 2, pp. 605-634.

McMahon, W., Burtwell, M.H. and Evans, M. (2005), Minimising Street Works Disruption: The Real Costs of Street Works to the Utility Industry and Society, UK Water Industry Research, London.

Marvin, S. and Slater, S. (1997), "Urban infrastructure: the contemporary conflict between roads and utilities", Progress in Planning, Vol. 48 No. 4, pp. 247-318.

Matthews, J.C., Allouche, E.N. and Sterling, R. (2015), "Social cost impact assessment of pipeline infrastructure projects”, Environmental Impact Assessment Review, Vol. 50, pp. 196-202.

Miles, M. and Huberman, A. (1994), Qualitative Data Analysis: An Expanded Sourcebook, Sage Publications, London.

New Roads and Street Works Act (1991), "New Roads and Street Works Act”, HMSO, London.

Niehaves, B., Plattfaut, R. and Becker, J. (2013), "Business process management capabilities: a multi-method study", Government Information Quarterly, Vol. 30 No. 3, pp. 217-225.

Perrott, S. (2002), "Theme: gender, the professions and public management: gender, professions and management in the public sector", Public Money and Management, Vol. 22 No. 1, pp. 21-24.

Sharp and McDermott (2001), Workflow Modelling - Tools for Process Improvement and Application Development, Artech House Publishers, London.

Son, H., Park, Y. and Kim, C. (2012), "Toward an understanding of construction professionals' acceptance of mobile computing devices in South Korea; an extension of the technology acceptance model", Automation in Construction, Vol. 28 No. 1, pp. 82-90.

Thong, J.Y.L., Yap, C. and Seah, K. (2000), "Business process reengineering in the public sector: the case of the housing development board in Singapore", Journal of Information Management Systems, Vol. 17 No. 1, pp. 245-270.

Tomassini, P. (2014), Mobile Highway Construction App - Improving State Operations, Pennsylvania Department of Transport, Harrisburg, PA.

Transport Research Laboratory (2009), "A charge structure for trenching in the highway”, Published Project Report No. PPR 386, Transport Research Laboratory, London.

W.K. Kellogg Foundation (2004), Logic Map Development Guide, W.K. Kellogg Foundation, Battle Creek, MI.

Walker, G. and Calvert, M. (2015), "Driver behaviour at road works", Applied Ergonomics, Vol. 51 No. 2, pp. 18-29.

Weerakkody, V. and Dhillon, G. (2008), "Moving from e-government to t-government; a study of process engineering challenges in a UK local authority context, International", Journal of Electronic Government Research, Vol. 4 No. 4, pp. 1-16.
Road works planning and coordination 
BEPAM

7,2

172
Weerakkody, V., Janssen, M. and Dwivedi, Y. (2011), "Transformational change and business process reengineering (BPR): lessons from the British and Dutch sector", Government Information Quarterly, Vol. 28 No. 3, pp. 320-328.

Wolbers, M., Evans, R.J.E., Holmes, M., Pasquire, C. and Price, A. (2005), "Construction management and lean thinking in highways maintenance", in Smith, S.D. (Ed.), Proceedings 28th Annual ARCOM Conference, Association of Researchers in Construction Management, Edinburgh, 3-5 September 2012, pp. 33-42.

Yin, R.K. (2014), Case Study Research Design and Methods, 5th ed., Sage Publications, London.

Zhang, X. (2016), "Comparative analysis of international practices in managing utilities road works", International Conference on Computational Modelling, Simulation and Applied Mathematics, Bangkok, 24-25 July.

\section{Corresponding author}

Rizwana Shaheen Hussain can be contacted at: rizwana.hussain@derby.gov.uk

For instructions on how to order reprints of this article, please visit our website: www.emeraldgrouppublishing.com/licensing/reprints.htm Or contact us for further details: permissions@emeraldinsight.com 